\title{
THE CONTROL OF HYPERACUTE REJECTION BY GENETIC ENGINEERING OF THE DONOR SPECIES
}

\author{
D. J. G. WHITE ${ }^{1}$, E. COZZI ${ }^{1}$, G. LANGFORD ${ }^{1}$, T. OGLESBY ${ }^{2}$, M.-W. WANG ${ }^{1}$, L. WRIGHT \\ and J. WALLWORK ${ }^{3}$
}

\begin{abstract}
SUMMARY
Activation of endogenous complement is inhibited both in the soluble phase and at the membrane surface by a group of structurally similar proteins. A possible solution to hyperacute rejection is to produce donor animals transgenic for human complement regulators. Mouse cells expressing the human complement regulatory proteins decay accelerating factor (DAF) or membrane cofactor protein (MCP) were produced both by hybridoma technology and by transfection with the appropriate cDNAs. The expression of either or both of these products protected the mouse cell from lysis by human (though not rabbit) complement in the presence of naturally occurring human anti-mouse antibody. This effect could be abrogated by the addition of monoclonal antibody against DAF or MCP. Hyperacute rejection of discordant organ xenografts is mediated by human complement. A 6.5 kilobase minigene for DAF has been microinjected into porcine fertilised ova. Forty-five pigs transgenic for human DAF have been produced. Of these, $65 \%$ transcribe message. The amount of message produced varied substantially from animal to animal and was independent of copy number integrated. Expression of human DAF on the porcine lymphocyte surface could be detected and this was able to downregulate human complement activation. Amounts of protein expressed on different tissues varied both from pig to pig and within animals from tissue to tissue. The pigs grow and develop normally with no evidence of ill effects due to possession of the transgene.
\end{abstract}

Vascular grafts transplanted between distantly related species are hyperacutely rejected minutes after revascularisation. Numerous investigations

From: ${ }^{1}$ Department of Surgery, School of Clinical Medicine, University of Cambridge, Cambridge, UK; ${ }^{2}$ The Howard Hughes Medical Institute at Washington University, St Louis, MO, USA; ${ }^{3}$ Papworth Hospital, Cambridgeshire, UK.

Correspondence to: Mr D. White, MRCPath, Department of Surgery, University of Cambridge, Douglas House, 18 Trumpington Road, Cambridge CB2 2AH. have demonstrated that complement is critically involved in this process, ${ }^{1,2}$ although the precise mechanisms by which this occurs are poorly understood. Platt et $a .^{3}$ have demonstrated that pig endothelium can be activated as assessed by the release of heparin sulphate by the fixation of $\mathrm{C} 3 \mathrm{~b}$ via the classical pathway. Forty and co-workers ${ }^{4}$ have demonstrated that platelet thrombus formation induced by classical pathway activation of complement causes rapid failure of rabbit hearts perfused with human blood. However, both Forty ${ }^{5}$ and others $^{6-8}$ have also demonstrated a role for the alternative pathway of complement in hyperacute xenograft rejection. The enzymatic cleavage of $\mathrm{C} 3$ by the $\mathrm{C} 3$ convertases is a key step in complementmediated destruction via both pathways and is regulated by a family of proteins termed the regulators of complemented activation (RCA). ${ }^{9}$ This family includes serum proteins (factor $\mathrm{H}$ and C4 binding protein), receptors (CR1 and CR2) and the membrane-bound proteins decay accelerating factor (DAF) and membrane cofactor protein (MCP).

Since DAF and MCP are believed to protect autologous tissue from endogenous complement activation, ${ }^{10}$ we sought to determine whether these human proteins could protect discordant mammalian cells from human complement-mediated destruction. These regulators of complement activation (RCAs) are, to a large extent, species specific. Transferring human RCA products to the membranes of animal tissues either biochemically or by transfection should confer protection against human complement on the animal tissue to a degree which may be sufficient to inhibit hyperacute rejection. Work has now progressed from tissue culture studies to encompass the whole animal. Here we describe the production of pigs transgenic for human DAF, the relationship between transcription and expression and the degree to which expression can protect the transgenic pig tissue from lysis by human complement. 


\section{MATERIALS AND METHODS}

Human/mouse cell hybrids generated by fusion of human Epstein-Barr virus (EBV)-transformed B cells with the non-secreting mouse myeloma X63$\mathrm{Ag} 8.653^{11}$ were screened for the presence of human chromosome 1 . This was performed by hybridisation with oligonucleotide primers specific for human chromosome 1 following polymerase chain reaction (PCR) amplification of DNA extracted from cell lines. Both upstream (5'-CCACAGGTGTAACATTCTGT-3') and downstream (5'-GAGATAGTGTGATCTGAGGC-3') primers were from the sequence of human anti-thrombin II (AT3) gene. ${ }^{12} \mathrm{~A}$ human/mouse hybridoma, B10 (which secretes human anti-tetanus antibody: N. HughesJones, personal communication), retained human chromosome 1. An EBV-transformed human tonsilar B cell line, T5, and a mouse/mouse hybridoma, DB3 (also produced by fusion with X63- $\mathrm{Ag} 8.653^{13}$ ), were used as negative and positive controls respectively.

Chromium release assay was performed as previously described. ${ }^{14}$ Complement was absorbed at $+4^{\circ} \mathrm{C}$ with mouse spleen cells $(2 \mathrm{ml}$ per spleen $)$ to remove lytic naturally occurring anti-mouse antibodies. Human or pig serum was used as a source of naturally occurring antibodies and was heat-inactivated at $56^{\circ} \mathrm{C}$ for 30 minutes. Monoclonal antibodies were added to labelled cells immediately prior to the start of the assay at $10 \mu \mathrm{g} / \mathrm{ml}$.

Mouse fibroblasts were transfected with DAF and MCP cDNAs subcloned in the forward orientation into the EcoRI site of the expression vector pHBapr1-neo. ${ }^{15}$ An additional construct, in which the MCP sequences were cloned into the expression vector in the reverse orientation, was isolated and used as a control. Cloned cDNA for DAF and MCP was obtained and characterised as previously described. ${ }^{16,17}$ Plasmid DNA was prepared using the pZ523 kit (5'-3' Inc., West Chester, PA, USA). NIH 3T3 cells were transfected utilising Lipofectin (Bethesda Research Laboratories, Gaithersburg, MD, USA) and then cultured for 2 days in Dulbecco-modified Eagle's medium supplemented with $10 \%$ horse serum following which Geneticin (Gibco, Grand Island, NY, USA) was added to the medium at an active concentration of $0.5 \mathrm{mg} / \mathrm{ml}$. Cells were subsequently maintained in this medium. DAF transfectants were further selected by fluorescence-activated cell sorting (EPIC 75, Coulter Corp., Hialea, FL, USA).

\section{Production of Transgenic Pigs}

Pronuclear-stage embryos were collected by midventral laparotomy from the oviducts of 7- to 10month-old mature gilts 49-52 hours after superovulation, the gilts having been inseminated 20 and
26 hours earlier. Visualisation of the pronucleus was achieved by centrifugation of the ova at $15000 \mathrm{~g}$ for 3 minutes. These ova were then microinjected using an inverted microscope with Nomarski optics and micromanipulaors. DNA was injected until the ova increased their diameter by approximately $50 \%$. Injected ova were transferred surgically to both oviducts of recipient gilts whose oestrous cycles were either synchronous with or 24 hours behind those of the donors.

A total of 2443 ova microinjected with the DAF minigene were transferred to recipient gilts. Of these, $49(65 \%)$ produced 311 offspring. Forty-six $(14.8 \%)$ of these offspring were identified by dot and southern blot analysis (using DNA isolated from ear biopsy samples) as having incorporated into their genome between 1 and 30 copies of the DAF minigene per cell. Expression of the transgene in the peripheral blood mononuclear cells was determined by RT-PCR using primers designed to span an intron/exon boundary and by Northern analysis. Messenger RNA for human DAF was detected in $67 \%$ of the transgenic pigs. The level of RNA varied from pig to pig and was found to be independent of the number of genes integrated into the genome, sex or growth rate.

\section{RESULTS}

Fluorescence-activated cell sorting (FACS) analysis using the monoclonal antibodies 1A10(17) and E4.3(20) showed that the selected human/mouse hybrid, B10, expressed both human DAF and MCP, as did the human tonsilar cell line T5. The mouse/ mouse hybrid did not express these RCA products. Fig. 1a shows that naturally occurring human antimouse antibodies and human complement were able to lyse DB3, (the mouse/mouse hybridoma) but not B10 (the human/mouse hybridoma). Both cell types were killed by rabbit complement (Fig. 1b). T5 exposed to pig anti-human antibodies was lysed in the presence of rabbit complement but not human complement (data not shown).

Cell lines transfected with the DAF or MCP constructs were isolated and shown by FACS analysis to be expressing DAF or MCP. The MCP transfectant (unsorted) expressed approximately $1 \times$ $10^{6}$ copies per cell (in the range of a malignant epithelial cell line ${ }^{18}$ ) while the DAF transfectant (sorted twice) expressed approximately 30000 copies per cell, similar to a normal peripheral nucleated cell. The cytoprotective effect of transfecting the individual genes for DAF or MCP was tested by treating all three cell lines (the two expressing cell lines and the control transfected in the reverse orientation) with human complement and naturally occurring human anti-mouse antibodies. The mouse fibroblasts expressing human DAF (Fig. 2a) or MCP (Fig. 2b) 


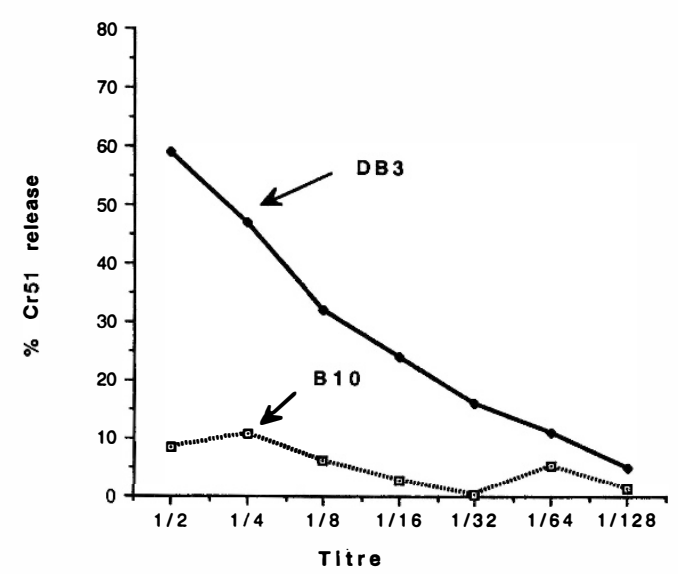

(a)

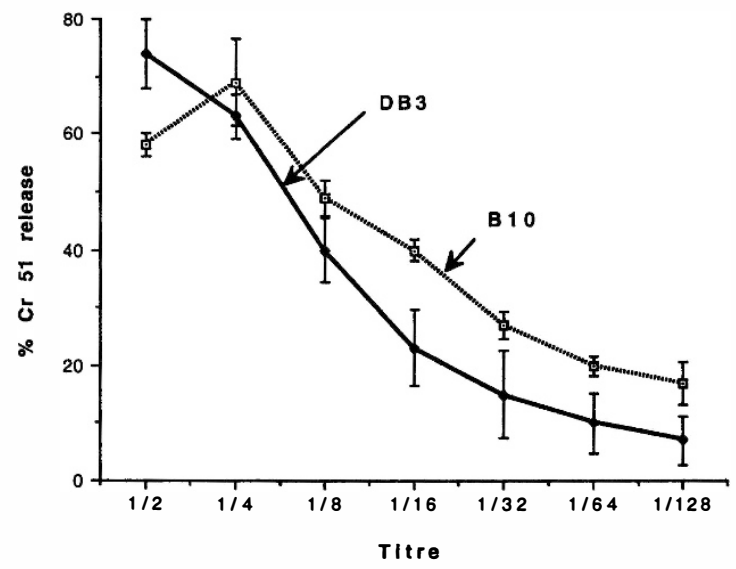

(b)

Fig. 1. A comparison between the ability of human (a) and rabbit complement $(b)$, in the presence of 'naturally occurring' human anti-mouse antibody, to lyse either a mouse/human hybrid (B10) possessing human chromosome 1 and expressing human $D A F$, or a mouse/mouse hybrid control (DB3).

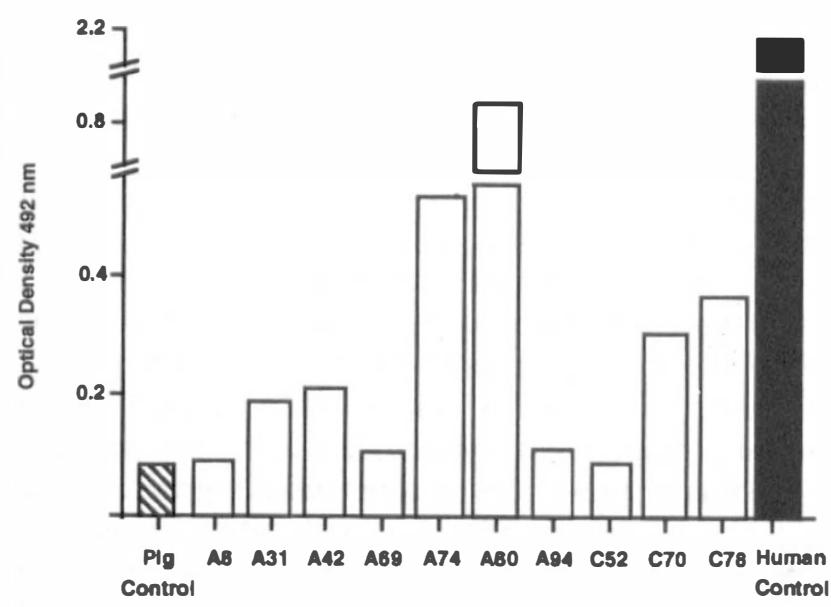

Fig. 3 Comparison of the expression of human DAF on $P B M C$ lysates from transgenic pigs.

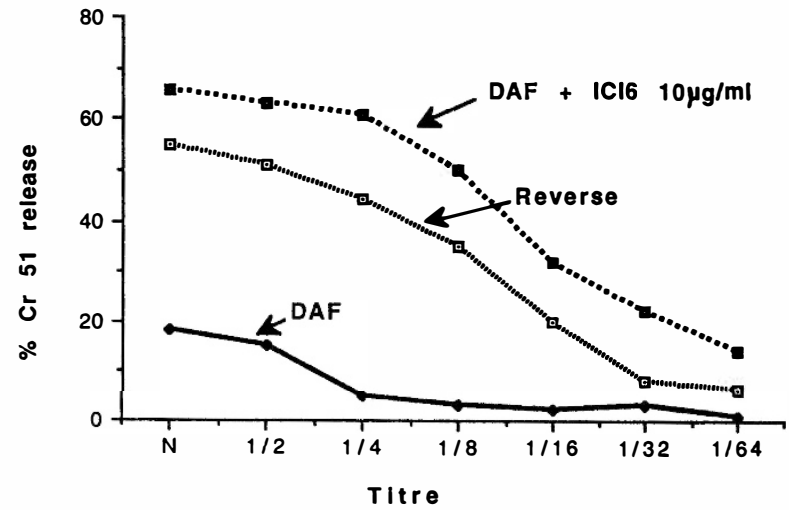

(a)

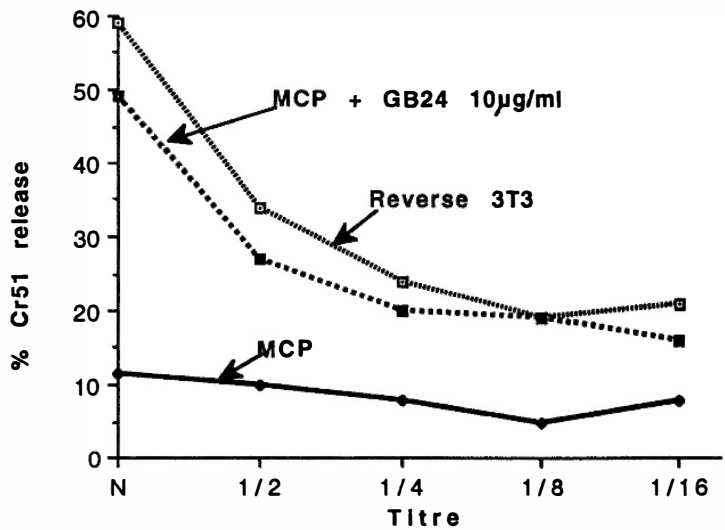

(b)

Fig. 2. The cytoprotective effect of transfecting a mouse fibroblast cell line (3T3 NIH) with DAF (a) or MCP (b). Controls are the transfected cell line blocked with monoclonal antibody against the expressed product and $3 T 3$ cell line transfected with the MCP gene in the reverse orientation (Reverse).

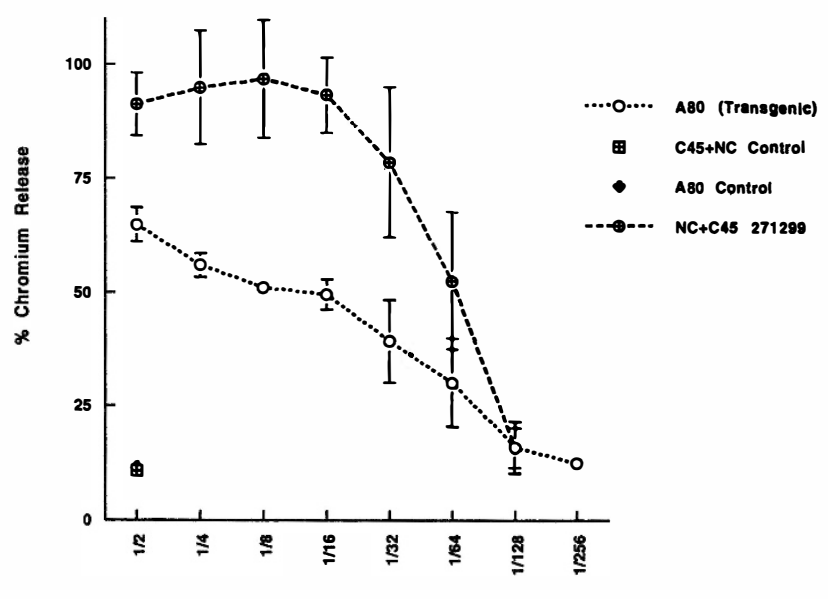

Human Serum Dilution

Fig. 4. Chromium release from normal and transgenic porcine lymphocytes exposed to naturally occurring anti-pig antibodies and human complement. 

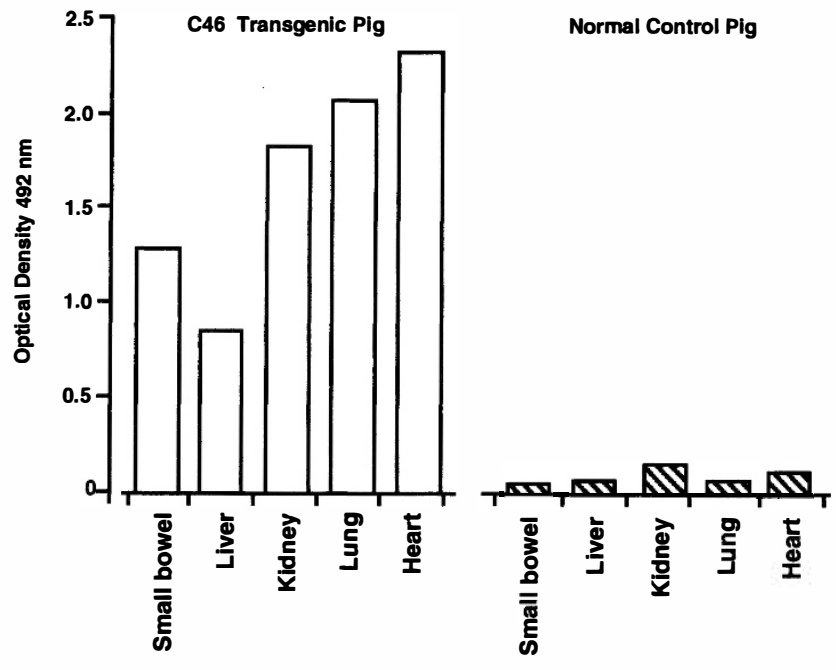

Fig. 5. Expression levels of human DAF from various tissues from a transgenic and normal pig.

are almost completely protected from lysis by human complement while the reverse MCP control line was lysed. Appropriate controls demonstrated that this cell lysis was complement mediated. The protective effect was abrogated by the addition of monoclonal antibodies against DAF $\left(\mathrm{IC} 6^{19}\right)$ or MCP $\left(\mathrm{GB} 24^{20}\right)$ to the appropriate assay. A non-specific monoclonal served as a control in these assays.

\section{Expression of DAF Protein on Lymphocytes}

Pigs transgenic for human DAF (hDAF) were studied for the expression of protein on the surface of their peripheral blood mononuclear cells (PBMC) by radioimmunoassay (Fig. 1a). hDAF could be detected in $84 \%$ of pigs producing RNA. No protein was found in RNA-negative animals. hDAF expression on the cell surface of PBMC varied considerably from pig to pig. The transgenic pig with the highest hDAF levels (A80) exhibited a fivefold lower expression compared with that seen on human PBMC (Fig. 3).

Functional protection from human complement by the presence of hDAF was assessed by standard twostage chromium release assays. Because of the outbred nature of pigs appropriate controls were limited to 'normal' pigs or non-expressing transgenics. As with expression levels, the amount of protection provided varied from pig to pig. The insensitivity of the assay made it impossible to perform a linear correlation analysis between expression levels and protection, but pigs with the greatest amount of hDAF exhibited the most protection. Thus A80 lymphocytes were protected by hDAF from lysis by human complement to a degree comparable with the amount of protection seen in normal (or transgenic) pig lymphocytes being lysed by porcine complement (Fig. 4).

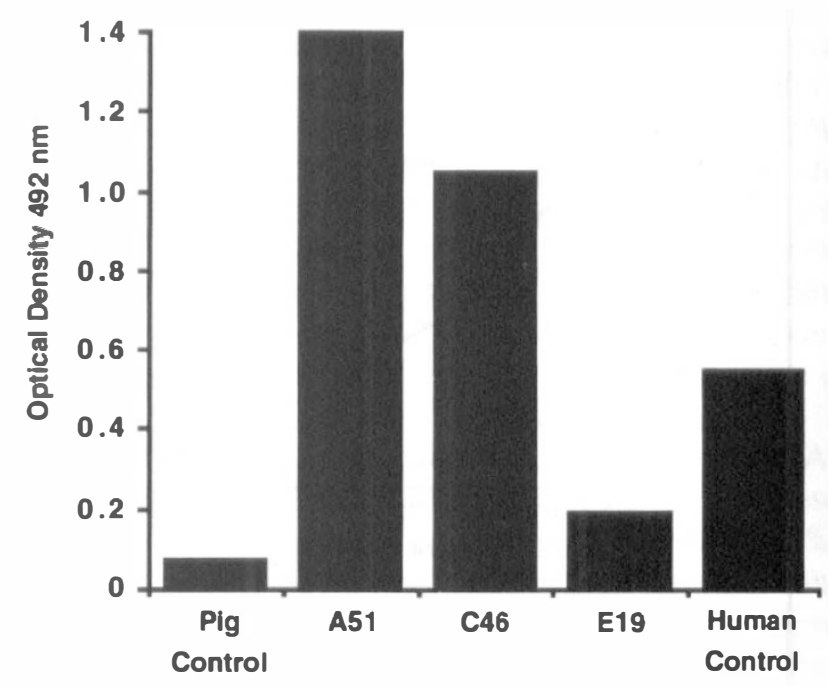

Fig. 6. Comparison of the level of human DAF expressed on the liver of three transgenic pigs and man.

\section{Expression of hDAF in Other Tissues}

Production of transgenics requires that founder animals be retained for breeding and that the offspring be appropriately backcrossed to produce homozygotes. However, during the course of these studies three transgenics have been killed, giving access to other tissues for analysis. Fig. 5 shows expression levels from tissues taken from one such pig. Comparison of the level of hDAF in the tissues of these pigs with that seen in comparable human tissues demonstrated that the transgenics were expressing up to threefold more than human tissues (Fig. 6).

\section{DISCUSSION}

A precise understanding of the steps of the complement reaction that participate in hyperacute xenograft rejection will be needed to design appropriate strategies for therapeutic intervention. ${ }^{21,22}$ This paper describes experiments demonstrating the complement regulatory activity of human DAF and MCP on the surface of hybrid and transfected mouse cells. These data also provide a demonstration of cytoprotection from complement by genetic manipulation of the target cell. The assay used is in many respects analogous to the mechanisms involved in hyperacute xenograft rejection.

The data presented here also demonstrate that it is possible to produce pigs transgenic for hDAF which can survive and grow and mature sexually in a normal porcine environment. The $2.5 \%$ success rate in producing these pigs is substantially greater than the $0.5 \%$ previously reported with other constructs. The factors contributing to this increase were a high pregnancy rate and large litters rather than any particular property of the construct injected. Expression of hDAF in the transgenes appeared to be 
dependent upon the site of integration and was independent of copy number. Our previous studies with transgenic mice had demonstrated that the inclusion of the genomic promoter region was essential for expression of the protein. The large number of transgenic pigs produced should enable us to select, from analysis of the offspring, founders which by chance have high expression levels of $\mathrm{hDAF}$ in appropriate tissues. The very high expression levels seen in the tissues of two of the three transgenics killed was not predicted by our mouse studies. In theory when such animals are bred to homozygosity their tissues should express 6 times human levels of hDAF. Our intention at the outset of these studies was to produce pigs transgenic for the human complement regulators DAF, MCP and CD59. Transfection studies have demonstrated a linear relationship between protection and cell surface concentration. If no synergistic activity exists in the processes of complement regulation it might be that pigs expressing sufficient amounts of DAF could be immune to the complement-mediated lesions of hyperacute xenograft rejection. Once such lesions have been avoided what other forms of immunological damage such xenografts would attract is largely unknown.

We thank Drs N. Hughes-Jones, M. Davitz and N. K. Spurr for the gift of reagents; also Drs A. Williams, C. Millstein and J. Bogaerde for helpful discussions. this work was supported by the Howard Hughes Foundation and Imutran Ltd, Cambridge.

Key words: Complement, Transgenic pig, Xenograft.

\section{REFERENCES}

1. Paul LC. Mechanism of humoral xenograft rejection. In: Cooper DKC, Kemp E, Reemstma K, White DJG, editors. Xenografting: the transplantation of organs and tissues between species. Berlin: Springer-Verlag, 1991:47-79.

2. Perper RJ, Najarian JS. Experimental renal heterotransplantation in widely divergent species. Transplantation 1966;4:377-81.

3. Platt JL, Vercellotti GM, Dalmasso AP, Matas AJ, Bolman RM, Najarian JS, Bach FH. Transplantation of discordant xenografts: a review of progress. Immunol Today 1990;11:450-6.

4. Forty J, Watson CJ, Carey N, White DJG, Wallwork J. Perfusion of rabbit hearts with human blood results in immediate graft thrombosis which is temporally distinct from hyperacute rejection. Transplant Proc (in press).

5. Forty J, Carey N, White DJG, Wallwork J. Hyperacute rejection of rabbit hearts by human blood is mediated by the alternative pathway of complement. Transplant Proc (in press).

6. Johnston PS, Lim SML, Wang MW, Wright L, White DJG. Hyperacute rejection of xenografts in the complete absence of antibody. Transplant Proc 1991;23:877-9.

7. Miyagawa S, Hirose H, Shirakura R, Naka Y, Nakata $\mathrm{S}$, Kawashima Y, et al. The mechanism of discordant xenograft rejection. Transplantation 1988;46:825-30.

8. Schilling A, Land W, Pratschke E, Brendel W.
Dominant role of complement in the hyperacute xenograft rejection reaction. Surg Gynecol Obstet 1976;142:29-35.

9. Rey-Campos J, Rubinstein P, Rodriguez-de-Cordoba S. A physical map of the human regulator of complement activation gene cluster linking the complement genes CR1, CR2, DAF, and C4BP. J Exp Med 1988;167:664-9.

10. Nose M, Katoh M, Okada N, Kyogoku M, Okada H. Tissue distribution of HRF 20, a novel factor preventing the membrane attack of homologous complement, and its predominant expression on endothelial cells in vivo. Immunology 1990;70:145-9.

11. Kearney JF, Radbruch A, Liesegang B, Rajewesky K. A new mouse myeloma cell line that has lost immunoglobulin expression but permits the construction of antibody secreting hybrid cell lines. Immunology 1979;123:1548-50.

12. Wu S, Seino S, Bell GI. Human anti-thrombin II (AT3) gene length polymorphism revealed by the polymerase chain reaction. Nucleic Acids Res 1989;17:6433-7.

13. Wright LJ, Feinstein A, Heap RB, Saunders JC, Bennett RC, Wang MW. Progesterone monoclonal antibody blocks pregnancy in mice. Nature 1982;295:415-7.

14. Davies HffS, Taylor JE, White DJG, Binns RM. Major transplantation antigens of pig kidney and liver: comparison between whole organs and their parenchymal constituents. Transplantation 1978;25:290-5.

15. Fuhlbrigge RC, Fine SM, Unanue ER, Chaplin DD. Expression of membrane interleukin 1 by fibroblasts transfected with murine interleukin $1 \mathrm{cDNA}$. Proc Natl Acad Sci USA 1988;85:5649-53.

16. Caras IW, Davitz MA, Rhee L, Weddell G, Martin DWJ, Nussenzweig V. Cloning of decay-accelerating factor suggests novel use of splicing to generate two proteins. Nature 1987;325:545-9.

17. Lublin DM, Liszewski MK, Post TW, Arce MA, LeBeau MM, Rebentisch MB, et al. Molecular cloning and chromosomal localisation of human membrane cofactor protein (MCP): evidence for inclusion in the multigene family of complement-regulatory proteins. J Exp Med 1988;168:181-94.

18. Sparrow RL, McKenzie IFC. Hu Ly-m5: a unique antigen physically associated with HLA molecules. Hum Immunol 1983; 7:1-15.

19. Cho S-W, Oglesby TJ, Hsi BL, Adams EM, Atkinson JP. Characterisation of three monoclonal antibodies to membrane cofactor protein (MCP) of the complement system and quantification of MCP by radioassay. Clin Exp Immunol 1991;83:257-61.

20. Fujita T, Kamato T, Tamura N. Characterisation of functional properties of $\mathrm{C} 4$ binding protein by monoclonal antibodies. J Immunol 1985;134:3320-4.

21. Rodriguez de Cordoba S, Dykman TR, GinsbergFellner F, Ercilla G, Aqua M, Atkinson JP, Rubenstein P. Evidence for linkage between loci coding for the binding protein for the fourth component of complement (C4Bp) and for the $\mathrm{C} 3 \mathrm{~b} / \mathrm{C} 4 \mathrm{~b}$ receptor. Proc Natl Acad Sci USA 1984;81:7890-2.

22. Weiss JH, Morton CC, Bruns GAP, Weis JJ, Klickstein LB, Wong WW, Fearon DT. not known. J Immunol 1987;138:312-5. 